\title{
Energy dissipation at the rupture front of laboratory earthquakes
}

\section{Other Conference Item}

\section{Author(s):}

Kammer, David S. (1); McLaskey, Gregory C.

Publication date:

2021-05

Permanent link:

https://doi.org/10.3929/ethz-b-000488172

\section{Rights / license:}

Creative Commons Attribution 4.0 International

\section{Originally published in:}

EGUsphere, https://doi.org/10.5194/egusphere-egu21-3975 


\title{
EGU21-3975
}

https://doi.org/10.5194/egusphere-egu21-3975

EGU General Assembly 2021

(c) Author(s) 2021. This work is distributed under

the Creative Commons Attribution 4.0 License.

\section{Energy dissipation at the rupture front of laboratory earthquakes}

\author{
David Kammer ${ }^{1}$ and Gregory McLaskey ${ }^{2}$ \\ ${ }^{1}$ ETH Zurich, Institute for Building Materials, Switzerland (dkammer@ethz.ch) \\ ${ }^{2}$ Civil and Environmental Engineering, Cornell University, Ithaca, NY, USA
}

The energy dissipated during the friction weakening process at the front of an earthquake rupture, which is known as the fracture energy, is a key earthquake property. It directly affects the nucleation, propagation and arrest of earthquake ruptures, and, is therefore related to important questions, including the maximum possible size of earthquakes at a given fault section. However, estimating the fracture energy in the field is a difficult task and current approaches remain limited. In this work, we present near-fault strain measurements of large-scale laboratory earthquakes on a granite fault. The strain measurements present high-frequency fluctuations while the fault is sliding. These strain fluctuations are indicative of rupture fronts that propagate across the entire fault and occasionally reflect at the boundaries. Here, we will characterize these strain fluctuations by applying fracture-mechanics theory. We will demonstrate that the shape and time scales of the strain fluctuations are well described by the proposed analytical solution. We will further show that by fitting the amplitude of the theory to the experimental measurement, we can estimate the local fracture energy. We apply this process to determine the fracture energy for secondary rupture fronts, which appear within the sliding rupture area. The results are consistent with fracture energy estimates from laboratory-earthquake arrest experiments, but are orders of magnitude lower than reported values from small-scale rotary shear friction experiments. We will discuss the implications and potential of these observations. 